\title{
Effect of expiratory loaded breathing during moderate exercise on intercostal muscle oxygenation
}

\author{
Quentin Bretonneau, Aurélien Pichon, Claire de Bisschop \\ Faculté des Sciences du Sport, Laboratoire 'MOVE'(EA 6314), Université de Poitiers, France
}

\begin{abstract}
Background: In patients with obstructive lung disease, maintaining adequate ventilation during exercise may require greater contraction of the respiratory muscles, which may lead to a compression of muscle capillaries. Furthermore, dynamic hyperinflation $(\mathrm{DH})$ is frequent during exercise in these patients, as it allows to reach higher expiratory flows and to satisfy respiratory demand. However, in such situation, intercostal muscles are likely to be stretched, which could affect the diameter of their capillaries. Thus, in a context of high level of expiratory resistance, intercostal muscle oxygenation may be disturbed during exercise, especially if $\mathrm{DH}$ occurs.

Methods: Twelve participants (22 \pm 2 years) performed two sessions of moderate exercise (20 min) by breathing freely with and without a $20-\mathrm{cmH}_{2} \mathrm{O}$ expiratory threshold load (ETL). Tissue saturation index (TSI) and concentration changes from rest $(\Delta)$ in oxygenated $\left(\left[\mathrm{O}_{2} \mathrm{Hb}\right]\right)$ and total haemoglobin $([\mathrm{tHb}])$ were measured in the seventh intercostal space using near-infrared spectroscopy. Respiratory, metabolic and cardiac variables were likewise recorded.

Results: Throughout exercise, dyspnea was higher and TSI was lower in ETL condition than in control ( $p<0.01)$. After a few minutes of exercise, $\Delta\left[\mathrm{O}_{2} \mathrm{Hb}\right]$ was also lower in ETL condition, as well as $\Delta[\mathrm{tHb}]$, when inspiratory capacity started to be reduced $(\mathrm{p}<0.05)$. Changes in $\left[\mathrm{O}_{2} \mathrm{Hb}\right]$ and dyspnea were correlated with changes in expiratory flow rate $(\mathrm{Vt} / \mathrm{Te})(\mathrm{r}=-0.66$ and 0.66 , respectively; $\mathrm{p}<0.05)$.

Conclusion: During exercise with ETL, impaired muscle oxygenation could be due to a limited increase in blood volume resulting from strong muscle contraction and/or occurrence of $\mathrm{DH}$.
\end{abstract}

Key words: Intercostal muscle oxygenation; NIRS; expiratory threshold load; exercise; dynamic hyperinflation.

Correspondence: Quentin Bretonneau, Université de Poitiers, Faculté des Sciences du Sport, Laboratoire 'MOVE' (EA 6314), 8, allée Jean Monnet, TSA 31 113, 86073 Poitiers, Cedex 9, France. Tel. +33.5.49454042.

E-mail: quentin.bretonneau@univ-poitiers.fr - ORCID id: https://orcid.org/0000-0002-9307-8688

Contributions: All the authors made a substantive intellectual contribution. All the authors have read and approved the final version of the manuscript and agreed to be accountable for all aspects of the work.

Conflict of interest: The authors declare that they have no competing interests, and all authors confirm accuracy.

Availability of data and materials: The data used to support the findings of this study are available from the corresponding author upon request.

Ethics approval and consent to participate: The protocol was approved by the Ethics Committee in Sport Science Research (CERSTAPS 2018-25-01-22). All subjects were informed about benefits and risks associated with their involvement in this study and gave their written informed consent. 


\section{Introduction}

Obstructive lung diseases are characterized by reduced maximal expiratory flows due to high levels of airway resistance. Physical capacity and self-reported quality of life in patients are impaired but regular physical activity can improve the trend $[1,2]$. However, exercise tolerance may be strongly limited, as a consequence of reduced ventilatory capacities, systemic alterations, comorbidities and deconditioning [3].

Expiratory flow limitation (EFL) and dynamic hyperinflation (DH) are the main respiratory consequences of obstructive lung diseases. EFL is defined by the inability to increase expiratory flow at a given lung volume despite an increase in driving pressure [4]. Higher flows can be generated due to DH, as tidal breathing is shifted to higher pulmonary volume. This rearrangement occurs frequently during exercise in patient with airway obstruction $[5,6]$. However, DH increases the work of inspiratory muscles $[7,8]$ and can exacerbate dyspnea $[9,10]$.

In patients with obstructive lung disease, the power produced by respiratory muscles is likely to be raised in order to counteract the respiratory load $[11,12]$. If $\mathrm{DH}$ occurs in addition, intercostal muscles could be stretched [13], which may squeeze blood vessels $[14,15]$. Thus, in a context of high level of expiratory resistance, blood perfusion may be altered in intercostal muscles during exercise, leading to impaired intercostal muscle oxygenation and metabolic imbalance. A few previous studies have investigated these changes in patients with airway obstruction [16] and in healthy subjects constrained by an external expiratory resistance [17]. However, the involvement of EFL and DH on the alteration of intercostal muscle blood perfusion during exercise remains to be specified.

The aim of this study was to shed light on ventilatory muscle adaptations facing up to high expiratory load and to its own consequence: dynamic hyperinflation, this situation being frequently observed during exercise in obstructive lung diseases. We evaluated the effect of a $20-\mathrm{cmH}_{2} \mathrm{O}$ expiratory threshold load (ETL) on intercostal muscle oxygenation during continuous moderate exercise in healthy subjects. Tissue oxygenation was measured using near-infrared spectroscopy (NIRS) and intercostal muscles were investigated. Impaired oxygenation was expected in the intercostal muscles during exercise with ETL, as were correlations between $\mathrm{DH}$, tissue oxygenation and dyspnea.

\section{Design and Methods}

\section{Participants}

Twelve healthy active men ( $22 \pm 2$ years) were included in this study. Anthropometric and pulmonary function data are given in Table 1. All subjects had normal pulmonary function values [18] and skinfold $<20 \mathrm{~mm}$ at the seventh left intercostal space [19].

\section{Study protocol}

\section{Experimental protocol}

Three sessions were scheduled. During the first session, a submaximal incremental exercise test $(50 \mathrm{~W} ;+30 \mathrm{~W}$ each $2 \mathrm{~min})$ was performed with a cycle ergometer (Corvival PET, Lode B.V., Groningen, Netherlands) up until $70 \%$ of the age-predicted maximal heart rate $(208-0.7 *$ age) [20]. The workload carried out at the target heart rate was imposed in the following two sessions (target workload).
At the beginning of the protocol in the second and third sessions, subjects were studied for 3 minutes, seated on the cycle (baseline). Afterwards, a 20- $\mathrm{cmH}_{2} \mathrm{O}$ expiratory threshold load (ETL, Threshold PEP, Respironics Inc., Murrysville, PA, USA) or a tube with an equivalent dead space and diameter as the ETL (placebo tube) was applied at the mouth for 5 min (rest). Immediately after, subjects cycled for $25 \mathrm{~min}$ at $60 \pm 5 \mathrm{rpm}$ (detailed in Figure 1). Intense physical exercise was not allowed 24 hours before the experimentation. The second and third sessions were randomly counterbalanced, separated by 7 days and scheduled at the same time of the day.

\section{Measurements and materials}

Anthropometry. Skinfold was assessed at the seventh left intercostal space with a skinfold caliper (Harpenden, British Indicators Ltd., St. Albans, England) and a whole-body bioelectrical impedance technique was used to assess body fat mass (Tanita BC418-MA, Tanita Corporation, Tokyo, Japan).

Pulmonary function tests. Slow and forced vital capacities (SVC and FVC, respectively) were evaluated at each session (Metalyzer3B, Cortex Biophysik GmbH, Leipzig, Germany) according to the ATS/ERS Task Force recommendations [21]. At the second and third sessions, EFL was measured several times during the protocol by the technique described by Johnson et al. [22]. Spontaneous flow-volume $(\dot{\mathrm{V}}-\mathrm{V})$ curves measured during the protocol were superimposed on the maximal $\dot{V}-\mathrm{V}$ curve (i.e. the reference curve of the day) measured a few minutes before the beginning of the protocol (Figure 1). To obtain this reference curve, at least three FVC maneuvers were performed with ETL or placebo tube after five minutes of adaptation (Figure 1). At the second and third session, IC was likewise measured several times during the protocol (Figure 1) to detect exercise-induced DH [22-24]. Measurements of IC also allowed the device to place correctly the spontaneous $\dot{V}-\mathrm{V}$ curve within the reference curve in order to evaluate EFL. A set of two maximal inspirations was performed at rest and the best maneuver (i.e. the one with the highest IC) was chosen as reference IC. During exercise, three single maximal inspirations were performed. A second trial was performed when the first maneuver had been disturbed (e.g., saliva swallowing during the maneuver).

Table 1. Anthropometric and pulmonary function characteristics. Absolute values Predicted values (\%)

\begin{tabular}{|c|c|c|}
\hline Weight (kg) & $72 \pm 10$ & \\
\hline Height (m) & $1.8 \pm 0.1$ & \\
\hline BMI $\left(\mathrm{kg} / \mathrm{m}^{2}\right)$ & $23 \pm 3$ & \\
\hline Body fat mass (\%) & $14 \pm 6$ & \\
\hline Left $7^{\text {th }}$ IS ATT (mm) & $3.7 \pm 1.5$ & \\
\hline ERV (L) & $1.6 \pm 0.3$ & \\
\hline IRV (L) & $3.1 \pm 0.6$ & \\
\hline IC (L) & $3.9 \pm 0.6$ & \\
\hline SVC (L) & $5.6 \pm 0.6$ & $104 \pm 10$ \\
\hline $\mathrm{FEV}_{1}(\mathrm{~L})$ & $4.9 \pm 0.6$ & $115 \pm 13$ \\
\hline FVC (L) & $5.8 \pm 0.6$ & $116 \pm 10$ \\
\hline $\mathrm{FEV}_{1} / \mathrm{FVC}(\%)$ & $85 \pm 6$ & $99 \pm 7$ \\
\hline $\mathrm{MMEF}_{25-75 \%}(\mathrm{~L} / \mathrm{sec})$ & $5.3 \pm 1.2$ & $110 \pm 26$ \\
\hline
\end{tabular}

Values are mean $\pm \mathrm{SD}$. BMI, body mass index; $\mathrm{ERV}$, expiratory reserve volume; $\mathrm{FEV}_{1}$, forced expiratory volume during the first second; FVC, forced vital capacity; IC, inspiratory capacity; IRV, inspiratory reserve volume; IS ATT, intercostal space adipose tissue thickness; $\mathrm{MMEF}_{25-75 \%}$, mean median expiratory flow between $25 \%$ and $75 \%$ of FVC and SVC, slow vital capacity. 
Intercostal muscle oxygenation. Near-infrared spectroscopy (NIRS) (Oxymon Mk-III, Artinis Medical Systems, Zetten, The Netherlands) was used to assess the tissue saturation index (TSI) and the concentration changes in oxygenated, deoxygenated and total hemoglobin in the intercostal muscles $\left(\Delta\left[\mathrm{O}_{2} \mathrm{Hb}\right], \Delta[\mathrm{HHb}]\right.$ and $\Delta[\mathrm{tHb}]$ respectively) $[17,25,26]$. The change in response to exercise was calculated from the resting period during which ETL or placebo tube was applied. The optode was placed in the seventh intercostal space, on the left side of the subject, between the midclavicular and the anterior axillary lines. As maximal penetration depth of the light is approximately half of the distance between transmitter and receiver [27], interoptode distance was adjusted between 3.3 and $4.8 \mathrm{~cm}$ according to adipose tissue thickness. A differential pathlength factor of 4 was chosen [28]. Wavelengths of 859 and 763 $\mathrm{nm}$ were used. Data were recorded at $10 \mathrm{~Hz}$ and exported at $1 \mathrm{~Hz}$ after running average filtering.

Ventilatory variables and gas exchanges. Inspiratory and expiratory times ( $\mathrm{Ti}$ and $\mathrm{Te}$ ) and tidal volume $(\mathrm{Vt})$ were measured breath-by-breath using the Metalyzer device (Cortex Biophysik $\mathrm{GmbH}$, Leipzig, Germany). Total respiratory time (Ttot), inspiratory duty cycle (Ti/Ttot), breathing frequency (BF) and ventilatory flow ( $\dot{V} E)$ were calculated, as mean inspiratory and expiratory flow rates $(\mathrm{Vt} / \mathrm{Ti}$ and $\mathrm{Vt} / \mathrm{Te})$. Oxygen consumption $\left(\dot{\mathrm{VO}}_{2}\right)$, carbon dioxide production $\left(\mathrm{VCO}_{2}\right)$ and end-tidal $\mathrm{CO}_{2}$ pressure $\left(\right.$ PetCO $\left.\mathrm{C}_{2}\right)$ were likewise recorded. Respiratory exchange ratio (RER) and respiratory equivalents in oxygen $\left(\dot{\mathrm{VE}}-\dot{\mathrm{V}}_{2}\right)$ and carbon dioxide $(\dot{\mathrm{V}}$ $\mathrm{E}-\dot{\mathrm{V}} \mathrm{CO}_{2}$ ) were calculated.

Dyspnea. Perception of dyspnea was assessed using the modified 0-10 Borg-scale, before each IC measurement [29]. Subjects were required to point on the scale the level of their respiratory discomfort.

Pulse oximetry. A pulse oximeter (Wrist-Ox2 3150, Nonin
Medical Inc., Plymouth, MN, USA) was placed at the right index to continuously record pulse haemoglobin oxygen saturation $\left(\mathrm{SpO}_{2}\right)$.

Cardiovascular parameters. A PhysioFlow device was used to measure stroke volume (SV), heart rate (HR) and cardiac output ( $\dot{\mathrm{Q}}$ c) non-invasively and beat-by-beat (PF-05, Manatec Medical, Poissy, France). A sphygmomanometer (Omron-M3, Health Care CO. Ltd, Kyoto, Japan) was used to measure systolic and diastolic blood pressure (SBP and DBP). At rest, mean arterial pressure (MAP) was calculated as follows: $\mathrm{MAP}=\mathrm{DBP}+1 / 3(\mathrm{SBP}-\mathrm{DBP})$. During exercise, $\mathrm{MAP}=\mathrm{DBP}+1 / 2(\mathrm{SBP}-\mathrm{DBP})$.

\section{Statistical analysis}

Statistical analysis was performed with Statistica (StatSoft Inc., Tulsa, OK, USA). In control and ETL conditions $\left(\mathrm{Ctrl}_{\mathrm{C}}\right.$ and $\left.\mathrm{ETL}_{\mathrm{C}}\right)$, data were analyzed at rest and at the $7^{\text {th }}$, the $12^{\text {th }}$, and the $17^{\text {th }}$ min of the constant exercise (7'EX, 12' EX and 17' EX). For variables recorded continuously, mean values were calculated from the last 30 s preceding IC measurements.

Following the verification of parametric conditions, a first twoway repeated measures ANOVA was performed to evaluate the effect of exercise (rest vs 7'EX) according to the conditions $\left(\mathrm{Ctrl}_{\mathrm{C}}\right.$ vs $\left.\mathrm{ETL}_{\mathrm{C}}\right)$. A second ANOVA was conducted to test the effect of exercise duration (7'EX, 12' EX and 17' EX) according to the conditions. A Tukey post-hoc analysis was performed when ANOVA was significant. To detect exercise-induced DH, each IC measured during exercise was compared with the corresponding one measured at rest. Hedges' g was calculated to define effect size. Correlation coefficients were assessed using the Pearson or Spearman test, according to Gaussian distribution. Values were expressed as mean \pm standard deviation (SD). Results were considered as significant for a $\mathrm{p}<0.05$.

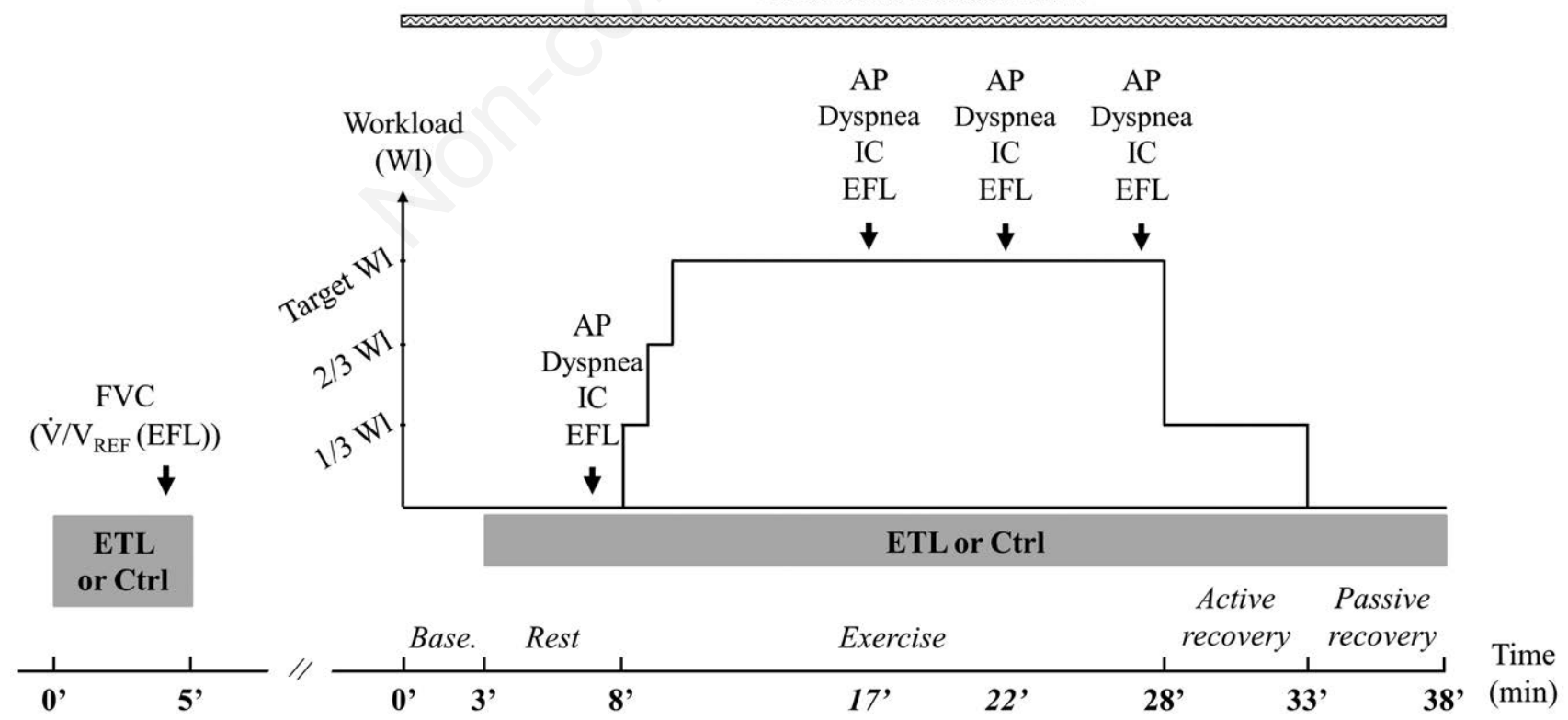

Figure 1. Protocol and time measurements. In experimental condition, a 20- $\mathrm{cmH}_{2} \mathrm{O}$ expiratory threshold load (ETL) was applied after three minutes of baseline (Base). In control condition (Ctrl), a tube with an equivalent dead space and diameter as the ETL was applied. With AP, arterial pressure; EFL, expiratory flow limitation; FVC, forced vital capacity; IC, inspiratory capacity and V-V $\mathrm{V}_{\mathrm{REF}}$ curve, reference flow-volume curve obtained from FVC maneuvers. Continuous measurements: intercostal muscle oxygenation and ventilatory, metabolic and cardiac variables. 


\section{Results}

Prior to the application of ETL or placebo tube, baseline values were not significantly different between conditions. The exercise workload associated with the target HR $(135.0 \pm 0.7 \mathrm{bpm})$ was $138 \pm 35 \mathrm{~W}$.

\section{Ventilatory variables}

Main ventilatory variables are shown in Table 2. At rest, Ti, $\mathrm{Ti} / \mathrm{Ttot}, \mathrm{Vt} / \mathrm{Te}$ and dyspnea were higher in $\mathrm{ETL}_{\mathrm{C}}$ than in $\mathrm{Ctrl}_{\mathrm{C}}(\mathrm{Ti}$ : $2.5 \mathrm{~s} v s 1.9 \mathrm{~s})$ while Te was lower $(2.1 \mathrm{~s} v s .2 .6 \mathrm{~s})$. Throughout exercise, Ti, Ti/Ttot and dyspnea were likewise higher with ETL (Ti: $1.5 \mathrm{~s} v s 1.1 \mathrm{~s}$ ). Te was $1.3 \mathrm{~s}$ regardless of conditions. BF and $\mathrm{Vt} / \mathrm{Ti}$ were lower with ETL while $\dot{\mathrm{VE}}$ did not change.

IC was not different between conditions at rest. In $\mathrm{ETL}_{\mathrm{C}}$, IC decreased from rest at the end of the exercise $(p<0.05)$ (Figure 2). EFL was never observed.

\section{Intercostal muscle oxygenation}

As shown in Figure 3, TSI was not different between conditions at rest and decreased in response to exercise in $\operatorname{ETL}_{\mathrm{C}}(\mathrm{p}<0.001)$. Throughout exercise, TSI was lower in $\mathrm{ETL}_{\mathrm{C}}$ than in $\mathrm{Ctrl}_{\mathrm{C}}$.

In $\mathrm{Ctrl}_{\mathrm{C}}, \Delta\left[\mathrm{O}_{2} \mathrm{Hb}\right]$ increased during exercise. In ETL $\mathrm{EL}_{\mathrm{C}} \Delta\left[\mathrm{O}_{2} \mathrm{Hb}\right]$ did not vary during exercise and was lower than in $\mathrm{Ctrl}_{\mathrm{C}} \cdot \Delta[\mathrm{HHb}]$ increased during exercise and tended to be higher in $\mathrm{ETL}_{\mathrm{C}}$ than in $\mathrm{Ctrl}_{\mathrm{C}}(\mathrm{p}=0.05) . \Delta[\mathrm{tHb}]$ increased during exercise in $\mathrm{Ctrl}_{\mathrm{C}}$ and in $\mathrm{ETL}_{\mathrm{C}}$. At 17'EX, $\Delta[\mathrm{tHb}]$ was different between the two conditions $(\mathrm{p}<0.05)$ as it stopped increasing in $\mathrm{ETL}_{\mathrm{C}}$.

\section{Gas exchanges}

$\dot{\mathrm{V}} \mathrm{O}_{2}$ and $\dot{\mathrm{V}} \mathrm{CO}_{2}$ were not affected by ETL. Mean overall $\dot{\mathrm{V}} \mathrm{O}_{2}$ and $\dot{\mathrm{V} C O}{ }_{2}$ values were $5.2 \mathrm{ml} / \mathrm{min} / \mathrm{kg}$ and $5.0 \mathrm{ml} / \mathrm{min} / \mathrm{kg}$ at rest, while at $17^{\prime} \mathrm{EX}$, mean values were $29.2 \mathrm{ml} / \mathrm{min} / \mathrm{kg}$ and 27.3 $\mathrm{ml} / \mathrm{min} / \mathrm{kg}$. As shown in Table 2, RER, $\dot{\mathrm{V} E} / \mathrm{VO}_{2}$ and $\dot{\mathrm{VE}} / \dot{\mathrm{V}} \mathrm{CO}_{2}$ at rest were higher in $\mathrm{ETL}_{\mathrm{C}}$ than in $\mathrm{Ctrl}_{\mathrm{C}}(\mathrm{p}<0.05)$ while $\mathrm{PetCO}_{2}$ was lower $(\mathrm{p}<0.01)$. In response to exercise, $\mathrm{V} E / \dot{\mathrm{V} \mathrm{O}}_{2}, \dot{\mathrm{V}} \mathrm{E} / \dot{\mathrm{V}}$

$\mathrm{CO}_{2}$ and $\mathrm{SpO}_{2}$ decreased in $\mathrm{ETL}_{\mathrm{C}}(\mathrm{p}<0.05)$. Throughout exercise, $\mathrm{SpO}_{2}$ was lower with $\mathrm{ETL}_{\mathrm{C}}$ than in $\mathrm{Ctrl}_{\mathrm{C}}(\mathrm{p}<0.05)$, while the other variables were not different between conditions.

\section{Cardiovascular variables}

HR was higher in $\mathrm{ETL}_{\mathrm{C}}$ than in $\mathrm{Ctrl}_{\mathrm{C}}(+12 . \mathrm{bpm}) . \mathrm{SV}, \dot{\mathrm{Q}}_{\mathrm{c}}$ and MAP were not different between conditions. $\dot{\mathrm{Q}} \mathrm{c}$ and MAP were $6.8 \mathrm{~L} / \mathrm{min}$ and $99 \mathrm{mmHg}$ at rest, while at 17' $\mathrm{EX}$, values were $19.2 \mathrm{~L} / \mathrm{min}$ and $130 \mathrm{mmHg}$, respectively.

\section{Correlations}

Correlations are displayed in Figure 4. In $\mathrm{ETL}_{\mathrm{C}}$, changes in $\left[\mathrm{O}_{2} \mathrm{Hb}\right]$ and dyspnea from rest to exercise $\left(\Delta=17^{\prime} \mathrm{EX}_{\mathrm{ETL}}-\mathrm{Rest}_{\mathrm{ETL}}\right)$ were correlated with changes in $\mathrm{Vt} / \mathrm{Te}(\mathrm{r}=-0.66$ and $\mathrm{r}=0.66$, respectively; $\mathrm{p}<0.05)$. In other words, the more the expiratory flow rate increased in response to exercise, the more $\left[\mathrm{O}_{2} \mathrm{Hb}\right]$ was impaired and dyspnea increased. Furthermore, changes in IC from $\mathrm{Ctrl}_{\mathrm{C}}$ to $\mathrm{ETL}_{\mathrm{C}}$ at the end of the exercise $\left(\Delta=17^{\prime} \mathrm{EX}_{\mathrm{ETL}}-17^{\prime} \mathrm{EX}_{\mathrm{CTRL}}\right)$ were correlated with changes in $\mathrm{Vt}(\mathrm{r}=0.71 ; \mathrm{p}<0.01)$ and $\mathrm{BF}(\mathrm{r}=$ $0.73 ; \mathrm{p}<0.01)$.

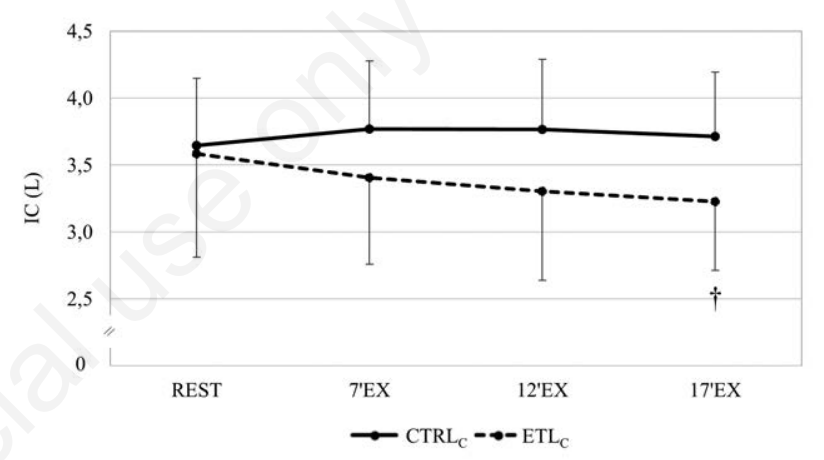

Figure 2. Inspiratory capacity (IC) at rest and at the $7^{\text {th }}\left(7^{\prime} \mathrm{EX}\right)$, the $12^{\text {th }}\left(12^{\prime} \mathrm{EX}\right)$ and the $17^{\text {th }}\left(17^{\prime} \mathrm{EX}\right)$ minute of the steady-state exercise in control and expiratory threshold load conditions $\left(\mathrm{Ctrl}_{\mathrm{C}}\right.$ and $\left.\mathrm{ETL}_{\mathrm{C}}\right)$. Values are mean $\pm \mathrm{SD}$. ${ }^{\dagger}$ different from Rest in the corresponding condition $(p<0.05$; effect size near to medium). Pairwise $t$-test; $\mathrm{n}=12$.

Table 2. Ventilatory variables and gas exchanges at rest and during exercise in control and expiratory threshold load conditions $\left(C T R L_{C}\right.$ and ETL $_{\mathrm{C}}$ ).

\begin{tabular}{|c|c|c|c|c|c|c|c|c|}
\hline & \multicolumn{3}{|c|}{ CTRL $_{C}$} & \multicolumn{3}{|c|}{ ETL $_{C}$} & \multicolumn{2}{|c|}{ Difference between conditions } \\
\hline & REST & $7^{\prime} \mathrm{EX}$ & $17^{\prime} \mathrm{EX}$ & REST & $7^{\prime} \mathrm{EX}$ & $17^{\prime} \mathrm{EX}$ & At rest & At EX \\
\hline \multicolumn{9}{|l|}{ Ventilatory variables } \\
\hline $\mathrm{Vt}(\mathrm{L})$ & $0.9(0.2)$ & $2.1(0.4)$ & $2.1(0.5)$ & $1.3(0.6)$ & $2.3(0.6)^{\#}$ & $2.2(0.5)$ & & \\
\hline $\mathrm{BF}(\mathrm{c} / \mathrm{min})$ & $14.0(2.4)$ & $25.0(4.3)$ & $26.2(3.8)$ & $14.2(4.3)$ & $21.1(4.9)^{\#}$ & $23.3(4.8)^{\S}$ & & $*$ \\
\hline$\dot{\mathrm{V}} \mathrm{E}(\mathrm{L} / \mathrm{min})$ & $11.7(2.8)$ & $51.7(9.8)$ & $54.2(10.2)$ & $17.1(4.7)$ & $47.3(8.2)^{\#}$ & $49.8(9.9)^{\S}$ & & \\
\hline Ti/Ttot (\%) & $41.7(7.3)$ & $46.6(3.3)$ & $47.1(3.9)$ & $54.6(7.3)$ & $53.3(3.8)$ & $53.1(5.2)$ & $* *$ & $* *$ \\
\hline $\mathrm{Vt} / \mathrm{Ti}(\mathrm{L} / \mathrm{sec})$ & $0.5(0.1)$ & $1.8(0.3)$ & $1.9(0.4)$ & $0.5(0.2)$ & $1.5(0.3)^{\#}$ & $1.6(0.4)^{\S}$ & & $*$ \\
\hline $\mathrm{Vt} / \mathrm{Te}(\mathrm{L} / \mathrm{sec})$ & $0.3(0.1)$ & $1.6(0.4)$ & $1.7(0.4)$ & $0.7(0.3)$ & $1.7(0.3)^{\#}$ & $1.8(0.4)^{\S}$ & $*$ & \\
\hline Dyspnea (Borg score) & $0.2(0.3)$ & $1.1(1.1)$ & $1.5(1.2)$ & $3.8(1.2)$ & $5.3(1.8)^{\#}$ & $5.6(2.1)$ & $* *$ & $* *$ \\
\hline \multicolumn{9}{|l|}{ Gas exchanges } \\
\hline RER & $0.89(0.10)$ & $0.96(0.03)$ & $0.94(0.02)$ & $1.01(0.16)$ & $0.93(0.05)$ & $0.92(0.05)$ & $*$ & \\
\hline$\dot{\mathrm{VE}} \dot{\mathrm{NO}}_{2}$ & $24.3(5.9)$ & $22.7(2.6)$ & $22.7(2.6)$ & $33.0(10.0)$ & $20.8(3.1)^{\circ}$ & $21.3(2.9)$ & $*$ & \\
\hline$\dot{\mathrm{VE}} / \dot{\mathrm{V}} \mathrm{CO}_{2}$ & $27.1(3.9)$ & $23.6(2.8)$ & $24.0(2.7)$ & $32.1(5.4)$ & $22.2(2.5)^{\circ}$ & $23.1(2.7)$ & $*$ & \\
\hline $\mathrm{PetCO}_{2}(\mathrm{mmHg})$ & $38.3(3.2)$ & $45.9(4.8)$ & $44.8(4.6)$ & $33.1(4.1)$ & $48.1(4.3)^{\#}$ & $47.4(4.9)^{\S}$ & $*$ & \\
\hline $\mathrm{SpO}_{2}(\%)$ & $96.6(1.3)$ & $95.6(2.1)$ & $94.6(1.3)$ & $97.2(1.0)$ & $93.5(2.3)^{\circ}$ & $92.8(2.4)$ & & $*$ \\
\hline
\end{tabular}

Values are mean (SD). During constant exercise, data were analysed at the $7^{\text {th }}\left(7^{\prime} \mathrm{EX}\right)$, the $12^{\text {th }}$ and the $17^{\text {th }}$ min $\left(17^{\prime} \mathrm{EX}\right)$. $\mathrm{BF}$, breathing frequency; PetCO ${ }_{2}$, end-tidal $\mathrm{CO}_{2}$ pressure; $\mathrm{RER}$, respiratory exchange ratio; $\mathrm{SpO}_{2}$, pulse haemoglobin oxygen saturation; Ti/Ttot, inspiratory duty cycle; $\mathrm{Vt}$, tidal volume; $\mathrm{Vt} / \mathrm{Te}$, expiratory flow rate; $\mathrm{Vt} / \mathrm{Ti}$, inspiratory flow rate; $\dot{\mathrm{VE}}$, ventilatory flow; $\dot{\mathrm{VE}} / \mathrm{VCO}_{2}$, ventilatory equivalent for $\mathrm{CO}_{2}$ and $\dot{\mathrm{V}} \mathrm{E} \dot{\mathrm{V}} \mathrm{O}_{2}$, ventilatory equivalent for $\mathrm{O}_{2} .{ }^{*}$ difference between conditions $\left({ }^{*} \mathrm{p}<0.05 ;{ }^{* *} \mathrm{p}<0.001\right) ;{ }^{\circ}$ difference between Rest and $7^{\prime} \mathrm{EX}$ in ETL $\mathrm{C}_{\mathrm{C}}$ only $(\mathrm{p}<0.05) ;{ }^{\sharp}$ difference between Rest and $7{ }^{\prime} \mathrm{EX}$ in ETLC only $(\mathrm{p}<0.05)$ or \# regardless of condition $(\mathrm{p}<0.05)$. 


\section{Discussion}

In patients with airway obstruction, high strength must be produced by respiratory muscles to overcome expiratory resistance, especially during exercise. In response to or in prevention of EFL, a shift in Vt toward higher lung volumes may also stretch intercostal muscles. As a consequence, blood vessels may be compressed. Thereby, a high level of expiratory resistance could lead to impaired tissue oxygenation in these muscles during exercise. To test this hypothesis, intercostal muscle oxygenation was assessed by NIRS while healthy subjects cycled with or without ETL. The main result of this study was that during moderate exercise, intercostal muscle oxygenation was altered when subjects breathed against ETL. DH was suggested to be involved in this impairment.

\section{Intercostal muscle oxygenation}

In response to exercise, increase in $\left[\mathrm{O}_{2} \mathrm{Hb}\right]$ was lower in ETL condition than in control. This may be explained by a rise in intercostal muscle oxygen consumption due to high expiratory effort. Indeed, as $\Delta[\mathrm{HHb}]$ tended to be higher than in control condition, greater oxygen extraction probably occurred in respiratory muscles. Otherwise, the more $\mathrm{Vt} / \mathrm{Te}$ increased from rest to exercise, the more $\left[\mathrm{O}_{2} \mathrm{Hb}\right]$ was impaired. As a rise in expiratory flow rate with ETL may suggest increased activity of respiratory muscles, greater oxygen extraction probably occurred in participants who more pronouncedly increased their $\mathrm{Vt} / \mathrm{Te}$.

In a previous study conducted in healthy subjects at rest [26], we suggested that compression of blood vessels due to vigorous breathing probably occurred in intercostal muscles when ETL was applied. As a result, the lower $\left[\mathrm{O}_{2} \mathrm{Hb}\right]$ observed in the muscles was
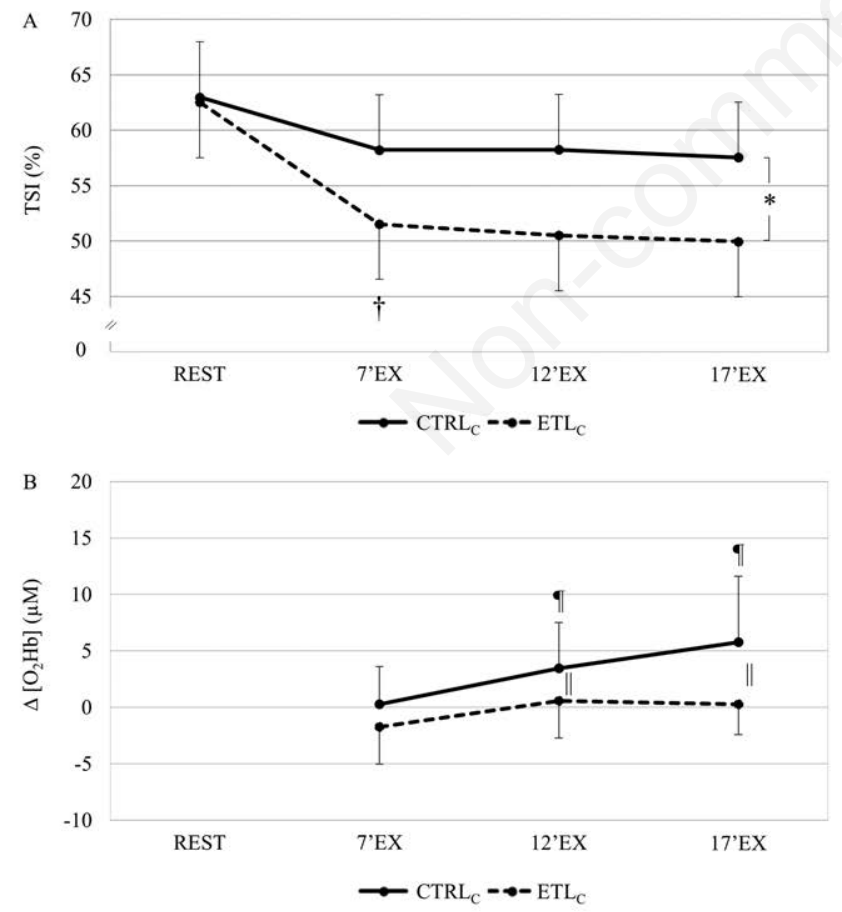

likely due to the lower blood volume (i.e. [tHb]). In the present study, according to changes in [tHb], the lower $\Delta\left[\mathrm{O}_{2} \mathrm{Hb}\right]$ in ETL condition could be explained, at least at the end of the exercise, by a limited increase in blood volume resulting from high intramuscular pressure. In agreement with our results, Vogiatzis et al. [30] demonstrated in patients with chronic obstructive pulmonary disease (COPD) that, when expiratory resistance was decreased at exercise by breathing an helium-enriched gas, oxygen delivery was improved in intercostal muscles. All of these results demonstrate that vascular compression may have an effect on muscle oxygenation. Lower changes in $\left[\mathrm{O}_{2} \mathrm{Hb}\right]$ in ETL condition could likewise be due to reduced systemic arterial oxygen content, as $\mathrm{SpO}_{2}$ was lower with ETL than in control condition throughout exercise, as observed in previous studies [17,31]. One hypothesis was that with ETL, higher pulmonary pressure could lead to compression of the alveolar blood vessels, thereby impairing the ability to transfer oxygen from the lung alveoli to the pulmonary capillaries [32].

In the present study, TSI was lower in ETL condition than in control throughout exercise. This result agrees with that of Athanasopoulos et al. [17]. In their study, healthy subjects performed a short and maximal exercise while the expiratory flow was limited by a Starling resistor to $1 \mathrm{l} / \mathrm{sec}$. In this context, oxygen saturation in intercostal muscles was impaired despite an increase in muscle blood flow. As TSI reflects dynamic balance between $\mathrm{O}_{2}$ supply and $\mathrm{O}_{2}$ consumption in the tissue [33], these results suggest that whatever the intensity of exercise, blood flow and/or oxygen delivery were probably insufficient to meet the metabolic needs of the respiratory muscles. Such a situation probably leads to exercise intolerance in COPD.
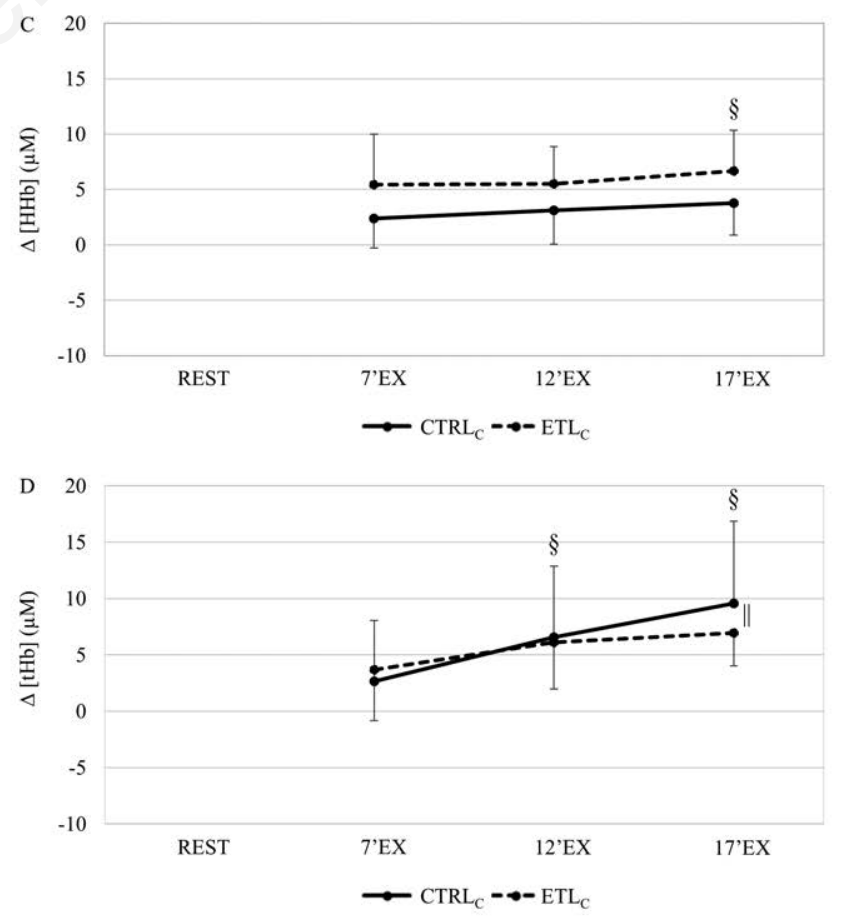

Figure 3. Intercostal muscle oxygenation in control and expiratory threshold load conditions $\left(\mathrm{Ctrl}_{\mathrm{C}}\right.$ and ETL $\left.\mathrm{EL}_{\mathrm{C}}\right)$. Values are mean $\pm \mathrm{SD}_{\text {. }}$ Tissue saturation index (TSI, panel A) at rest and at the $7^{\text {th }}\left(7^{\prime} \mathrm{EX}\right)$, the $12^{\text {th }}\left(12^{\prime} \mathrm{EX}\right)$ and the $17^{\text {th }}\left(17^{\prime} \mathrm{EX}\right)$ minute of the steady-state exercise. Concentration changes in oxyhaemoglobin $\left(\Delta\left[\mathrm{O}_{2} \mathrm{Hb}\right]\right.$, panel $\left.\mathrm{B}\right)$, deoxyhaemoglobin $(\Delta[\mathrm{HHb}]$, panel $\mathrm{C})$, and total haemoglobin $(\Delta[\mathrm{tHb}]$, panel $\mathrm{D})$. $\dagger$ different from Rest in the corresponding condition $(\mathrm{p}<\mathbf{0 . 0 1})$. Double bar because different from $\mathrm{Ctrl} \mathrm{C}_{\mathrm{C}}$ during exercise at the corresponding time $(p<0.05) ;{ }^{*}$ different from $\mathrm{Ctrl}_{\mathrm{C}}$ during exercise regardless of time $(\mathrm{p}<0.01$; effect size between large and very large); 'different from $7^{\prime} \mathrm{EX}$ in the corresponding condition $(\mathrm{p}<0.05)$; ${ }^{\S}$ different from $7^{\prime} \mathrm{EX}$ regardless of condition $(\mathrm{p}<0.05)$. Two-way repeated measures ANOVA; $\mathbf{n}=12$. 


\section{Dynamic hyperinflation}

$\mathrm{DH}$ refers to a rise in end-expiratory volume above the relaxation volume of the respiratory system. This shift is frequently observed in COPD patients, especially during exercise. In our study, DH was assessed according to change in IC from rest [9,24]. In ETL condition, IC was decreased at the end of the exercise, suggesting that DH appeared when exercise was lengthened. At the same time, EFL was not observed, so we can suppose that DH may allow subjects to achieve higher expiratory flows by shifting tidal breathing to higher lung volumes. Our results agree with data reported by Stark-Leyva et al. [34] in healthy subjects exercising with a $10-\mathrm{cmH}_{2} \mathrm{O}$ ETL. The reduction in IC of $400 \mathrm{ml}$ observed in our study was also consistent with that reported in COPD patients $[5,6]$. Otherwise, correlations showed that at the end of exercise, the more IC decreased from control to ETL condition, the more Vt decreased and BF increased. These results observed in healthy young subjects are consistent with ventilatory adaptations usually observed in patients with obstructive airway disease and DH [9].

\section{Dyspnea}

Dyspnea is frequently reported by COPD patients during exercise and is often the cause of the cessation of physical activity [10]. Dyspnea can be exacerbated by DH when it occurs during exercise because when tidal breathing is shifted to a higher lung volume, inspiratory muscle efferent is changed due to increased work of breathing. Concomitantly, the length of the respiratory muscles is modified, which disrupts the tension-length relationship of the muscle fibers and the ability of the respiratory muscles to produce strength $[35,36]$. Consequently, the mismatch between the inspiratory muscle efferent and the respiratory mechanical/muscular response might exacerbate respiratory discomfort [37]. In our study, perceived dyspnea was higher in ETL than in control condition. However, dyspnea did not cause cessation of exercise and was not correlated with DH. This result is consistent with our previous study [26]. This likewise agrees with the results of Aliverti et al. [38] and Guenette et al. [39]. In their study, the authors compared dyspnea in COPD patients with and without $\mathrm{DH}$ during exercise and did not find difference between the groups. This confirms that DH can lead to dyspnea, but dyspnea is not exclusively induced by $\mathrm{DH}$.

Besides, in the present study, we observed a correlation between dyspnea and $\mathrm{Vt} / \mathrm{Te}$, which is in agreement with the results of Kayser et al. [40] obtained in a similar context. Vogiatzis et al. [30] also demonstrated that, when expiratory muscle work was reduced in patients with COPD, dyspnea decreased. To sum up, all of these studies demonstrate that dyspnea during exercise may be induced not by only one factor, but rather by a set of causes including among which an increase in expiratory muscle load and $\mathrm{DH}$.

\section{Study limitations}

To test the effect of ETL on respiratory muscle oxygenation, intercostal muscles were chosen due to their compatibility with NIRS measurements, but their exact thicknesses were unknown. The depth of the NIRS measurement was based on theoretical external muscle thickness, 7-10 $\mathrm{mm}$ according to De Troyer et al. [41], and individual adipose tissue thickness. Nevertheless, it was not possible to specify the intercostal muscle investigated (i.e., external or internal). The contribution of myoglobin to global NIRS signals is also unknown, as is the impact of changes in skin perfusion / pigmentation during exercise. However, since the participants were their own controls, it can be considered that these

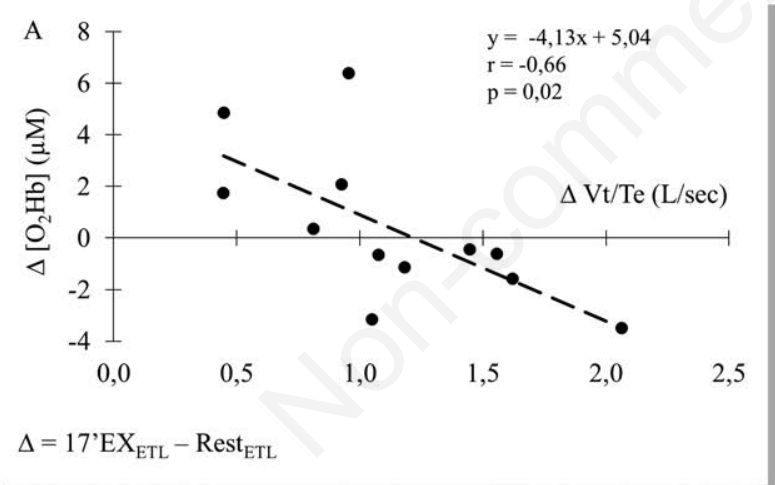

B

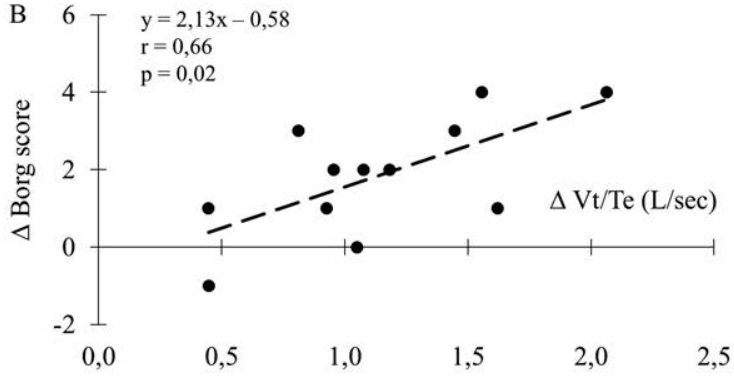

$\Delta=17$ 'EX $\mathrm{ETL}-$ Rest $_{\mathrm{ETL}}$

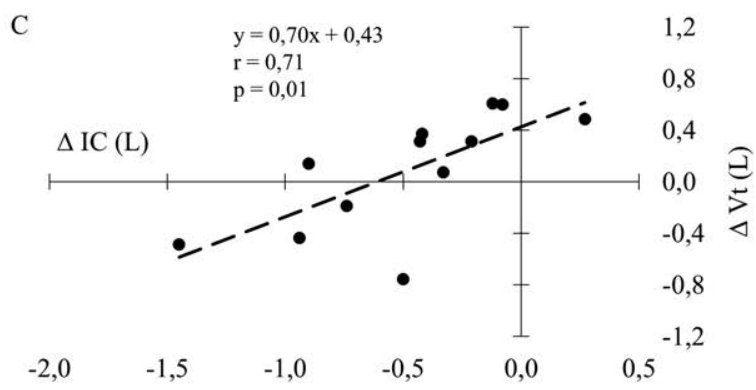

$\Delta=17^{\prime} \mathrm{EX}_{\mathrm{ETL}}-17^{\prime} \mathrm{EX}_{\mathrm{CTRL}}$

D

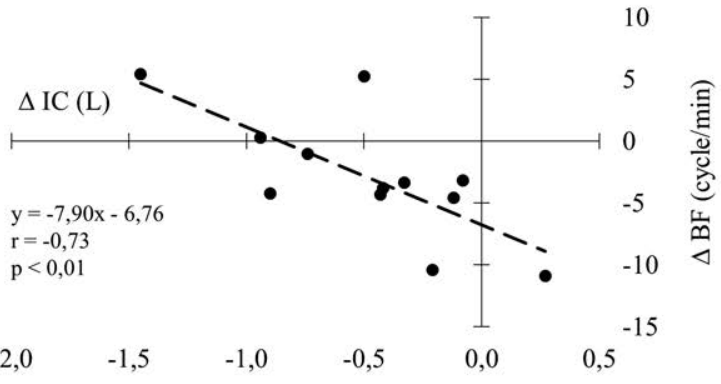

$\Delta=17^{\prime} \mathrm{EX}_{\mathrm{ETL}}-17^{\prime} \mathrm{EX} \mathrm{CTRL}$

Figure 4. Correlation between changes in oxyhaemoglobin concentration $\left(\Delta\left[\mathrm{O}_{2} \mathrm{Hb}\right]\right)$ and changes in expiratory flow rate $(\Delta \mathrm{Vt} / \mathrm{Te})$. $\left.\mathrm{B}\right)$ Correlation between changes in dyspnea $(\Delta$ Borg score) and $\Delta \mathrm{Vt} / \mathrm{Te}$. C) Correlation between changes in inspiratory capacity $(\Delta \mathrm{IC})$ and changes in tidal volume $(\Delta \mathrm{Vt})$. D) Correlation between $\Delta \mathrm{IC}$ and changes in breathing frequency $(\Delta \mathrm{BF})$. Pearson correlation, $\mathrm{n}=12$. 
changes and their potential impact on NIRS signals were not different between the two conditions (ETL and Ctrl).

In this study, assessments of EFL and DH were based on IC measurement and on the assumptions that total lung capacity (TLC) and the ability to perform maximal inspirations were not different between the successive maneuvers. These variables were not controlled in the present study because their evaluation requires the use of invasive techniques. Furthermore, several studies have shown, in healthy subjects and in patients with obstructive lung disease, that TLC and the ability to perform deep inspirations were not disturbed during exercise [12,23,24,42-44].

The activity of the intercostal muscles was not measured electromyographically during this study. However, the recruitment of these muscles has been demonstrated at rest in healthy subjects breathing with an expiratory resistance [45]. During exercise, a more important activity of intercostal muscles was likewise demonstrated in healthy subjects during loaded breathing condition $[34,46]$. Physioflow device accuracy has been sometimes contested as in airway obstructive contexts [47]. In our study, this device was only used to monitor cardiac output and other cardiovascular parameters that were not the main variables of the study. Nevertheless, results agree with those of the study by Lalande et al. [48] in which cardiac output was measured using echo-Doppler technique.

\section{Strength, clinical implication and perspective of the study}

This study was conducted to assess the functional and respiratory consequences of bronchial obstruction by having healthy subjects breathe against ETL during exercise. It focused on respiratory muscle oxygenation and aimed to investigate the links between muscle oxygenation, DH, EFL, and dyspnea. Consequently, the study may be of interest in diseases hallmarked by a high level of airway resistance. Furthermore, in order to assess the effect of ETL in a concrete situation, the intensity and duration of the exercise were chosen to be close to the modality recommended in patients with obstructive airway disease [49].

We demonstrated that during an exercise conducted with ETL applied at the mouth, intercostal muscle oxygenation was impaired and dyspnea increased. These deleterious effects seemed to be exacerbated when participants strongly increased their expiratory flow rate in response to exercise. Similar phenomena might occur in patients with obstructive lung disease, further impairing their already weak exercise capacities and accentuating their respiratory discomfort. As the use of positive expiratory pressure (PEP) devices is advised during exercise in COPD to prevent $\mathrm{DH}$ [50], alteration in respiratory muscles oxygenation must be known and taken into account by rehabilitation professionals. The counterpart of the PEP device should be studied more extensively to optimize its use or to assess the benefit risk ratio.

\section{Conclusion}

In conclusion, this study demonstrated that intercostal muscle oxygenation was impaired when healthy subjects performed a moderate steady-state exercise with ETL. More precisely, impairment in muscle oxygenation and dyspnea were more important in participants who had the higher increases in expiratory flow rate. This study also brought out that the increase in intercostal muscle blood volume, recorded during exercise, ceased when DH occurred. Thus, altered muscle oxygenation may have been due to an insufficient increase in local blood volume to match the higher metabolic demand in ETL context. Mechanical constraints applied on muscle capillaries were probably involved.

\section{Acknowledgements}

This study was supported in part by the European Union and the New Aquitaine region through the Habisan program (CPERFEDER).

Thanks to Wassmer Emeline for her technical help and the quality of her work during experimentations.

\section{References}

1. Heikkinen SAM, Quansah R, Jaakkola JJK, Jaakkola MS. Effects of regular exercise on adult asthma. Eur J Epidemiol 2012;27:397407.

2. Paneroni M, Simonelli C, Vitacca M, Ambrosino N. Aerobic exercise training in very severe chronic obstructive pulmonary disease: a systematic review and meta-analysis. Am J Phys Med Rehabil 2017;96:541-8.

3. Vogiatzis I, Zakynthinos S. Factors limiting exercise tolerance in chronic lung diseases. In: Terjung R, editor. Comprehensive physiology. Hoboken: J. Wiley \& Sons; 2012. Available from: http://doi.wiley.com/10.1002/cphy.c110015

4. Tantucci C. Expiratory flow limitation definition, mechanisms, methods, and significance. Pulm Med 2013;2013:1-6.

5. O'Donnell DE, Revill SM, Webb KA. Dynamic hyperinflation and exercise intolerance in chronic obstructive pulmonary disease. Am J Respir Crit Care Med 2001;164:770-7.

6. O'Donnell DE, Guenette JA, Maltais F, Webb KA. Decline of resting inspiratory capacity in COPD. Chest 2012;141:753-62.

7. Sliwinski P, Kaminski D, Zielinski J, Yan S. Partitioning of the elastic work of inspiration in patients with COPD during exercise. Eur Respir J 1998;11:416-21.

8. Chen S, Li Y, Zheng Z, Luo Q, Chen R. The analysis of components that lead to increased work of breathing in chronic obstructive pulmonary disease patients. J Thorac Dis 2016;8:2212-8.

9. O'Donnell DE, Bertley JC, Chau LK, Webb KA. Qualitative aspects of exertional breathlessness in chronic airflow limitation: pathophysiologic mechanisms. Am J Respir Crit Care Med 1997;155:109-15.

10. O'Donnell DE, Laveneziana P. Dyspnea and activity limitation in COPD: mechanical factors. COPD 2007;4:225-36.

11. Laveneziana P, Webb KA, Wadell K, Neder JA, O'Donnell DE. Does expiratory muscle activity influence dynamic hyperinflation and exertional dyspnea in COPD? Respir Physiol Neurobiol 2014;199:24-33.

12. Faisal A, Alghamdi BJ, Ciavaglia CE, Elbehairy AF, Webb KA, Ora $\mathrm{J}$, et al. Common mechanisms of dyspnea in chronic interstitial and obstructive lung disorders. Am J Respir Crit Care Med 2016;193:299-309.

13. Wilson TA, Legrand A, Gevenois P-A, De Troyer A. Respiratory effects of the external and internal intercostal muscles in humans. J Physiol 2001;530:319-30.

14. Leenaerts P, Decramer M. Respiratory changes in parasternal intercostal intramuscular pressure. J Appl Physiol 1990 1;68:86875.

15. Poole DC, Musch TI, Kindig CA. In vivo microvascular structural and functional consequences of muscle length changes. Am J Physiol-Heart Circ Physiol 1997;272:2107-14.

16. Vogiatzis I, Athanasopoulos D, Habazettl H, Aliverti A, Louvaris Z, Cherouveim E, et al. Intercostal muscle blood flow limitation during exercise in chronic obstructive pulmonary disease. Am J Respir Crit Care Med 2010;182:1105-13.

17. Athanasopoulos D, Louvaris Z, Cherouveim E, Andrianopoulos V, Roussos C, Zakynthinos S, et al. Expiratory muscle loading 
increases intercostal muscle blood flow during leg exercise in healthy humans. J Appl Physiol 2010;109:388-95.

18. Quanjer PH, Stanojevic S, Cole TJ, Baur X, Hall GL, Culver BH, et al. Multi-ethnic reference values for spirometry for the 3-95-yr age range: the global lung function 2012 equations. Eur Respir J 2012;40:1324-43.

19. Grassi B, Quaresima V. Near-infrared spectroscopy and skeletal muscle oxidative function in vivo in health and disease: a review from an exercise physiology perspective. J Biomed Opt 2016;21:091313.

20. Roy S, McCrory J. Validation of maximal heart rate prediction equations based on sex and physical activity status. Int J Exerc Sci 2015;8:318-30.

21. Miller MR, Hankinson J, Brusasco V, Burgos F, Casaburi R, Coates A, et al. Standardisation of spirometry. Eur Respir J 2005;26:31938 .

22. Johnson BD, Weisman IM, Zeballos RJ, Beck KC. Emerging concepts in the evaluation of ventilatory limitation during exercise. Chest 1999;116:488-503.

23. Yan S, Kaminski D, Sliwinski P. Reliability of inspiratory capacity for estimating end-expiratory lung volume changes during exercise in patients with chronic obstructive pulmonary disease. Am J Respir Crit Care Med 1997;156:55-9.

24. Guenette JA, Chin RC, Cory JM, Webb KA, O'Donnell DE. Inspiratory capacity during exercise: measurement, analysis, and interpretation. Pulm Med.2013;2013:1-13.

25. de Bisschop C, Beloka S, Groepenhoff H, van der Plas MN, Overbeek MJ, Naeije R, et al. Is there a competition for oxygen availability between respiratory and limb muscles? Respir Physiol Neurobiol 2014;196:8-16.

26. Bretonneau Q, Pichon A, de Bisschop C. Intercostal muscle oxygenation during expiratory load breathing at rest. Respir Physiol Neurobiol 2019;261:24-30.

27. Chance B, Dait MT, Zhang C, Hamaoka T, Hagerman F. Recovery from exercise-induced desaturation in the quadriceps muscles of elite competitive rowers. Am J Physiol-Cell Physiol 1992;262:76675.

28. van Beekvelt MCP, van Engelen BGM, Wevers RA, Colier WNJM. In vivo quantitative near-infrared spectroscopy in skeletal muscle during incremental isometric handgrip exercise. Clin Physiol Funct Imaging 2002;22:210-7.

29. Kendrick KR, Baxi SC, Smith RM. Usefulness of the modified 010 Borg scale in assessing the degree of dyspnea in patients with COPD and asthma. J Emerg Nurs 2000;26:216-22.

30. Vogiatzis I, Habazettl H, Aliverti A, Athanasopoulos D, Louvaris Z, LoMauro A, et al. Effect of helium breathing on intercostal and quadriceps muscle blood flow during exercise in COPD patients. Am J Physiol-Regul Integr Comp Physiol 2011;300:1549-59.

31. Aliverti A, Dellacà RL, Lotti P, Bertini S, Duranti R, Scano G, et al. Influence of expiratory flow-limitation during exercise on systemic oxygen delivery in humans. Eur J Appl Physiol 2005;95:229-42.

32. Nieman GF, Paskanik AM, Bredenberg CE. Effect of positive endexpiratory pressure on alveolar capillary perfusion. J Thorac Cardiovasc Surg 1988;95:712-6.

33. Ferrari M, Muthalib M, Quaresima V. The use of near-infrared spectroscopy in understanding skeletal muscle physiology: recent developments. Philos Trans R Soc Math Phys Eng Sci 2011;369:4577-90.

34. Stark-Leyva KN, Beck KC, Johnson BD. Influence of expiratory loading and hyperinflation on cardiac output during exercise. J Appl Physiol 2004;96:1920-7.

35. Braun NM, Arora NS, Rochester DF. Force-length relationship of the normal human diaphragm. J Appl Physiol 1982;53:405-12.

36. DiMarco AF, Romaniuk JR, Supinski G, Kowalski KE. Effects of lung volume on parasternal pressure-generating capacity in dogs. Exp Physiol 2000;85:331-7.

37. O'Donnell DE, Ora J, Webb KA, Laveneziana P, Jensen D. Mechanisms of activity-related dyspnea in pulmonary diseases. Respir Physiol Neurobiol 2009;167:116-32.

38. Aliverti A, Stevenson N, Dellaca RL, Lo Mauro A, Pedotti A, Calverley PMA. Regional chest wall volumes during exercise in chronic obstructive pulmonary disease. Thorax 2004;59:210-6.

39. Guenette JA, Webb KA, O'Donnell DE. Does dynamic hyperinflation contribute to dyspnoea during exercise in patients with COPD? Eur Respir J 2012;40:322-9.

40. Kayser B, Sliwinski P, Yan S, Tobiasz M, Macklem PT. Respiratory effort sensation during exercise with induced expiratory-flow limitation in healthy humans. J Appl Physiol 1997;83:936-47.

41. De Troyer A, Gorman RB, Gandevia SC. Distribution of inspiratory drive to the external intercostal muscles in humans. J Physiol 2003;546:943-54.

42. Stubbing DG, Pengelly LD, Morse JL, Jones NL. Pulmonary mechanics during exercise in normal males. J Appl Physiol 1980;49:506-10.

43. Stubbing DG, Pengelly LD, Morse JL, Jones NL. Pulmonary mechanics during exercise in subjects with chronic airflow obstruction. J Appl Physiol 1980;49:511-5.

44. Johnson BD, Scanlon PD, Beck KC. Regulation of ventilatory capacity during exercise in asthmatics. J Appl Physiol 1995;79:892901.

45. de Bisschop C, Montaudon M, Glénet S, Guénard H. Feasibility of intercostal blood flow measurement by echo-Doppler technique in healthy subjects. Clin Physiol Funct Imaging 2017;37:282-7.

46. Aliverti A, Iandelli I, Duranti R, Cala SJ, Kayser B, Kelly S, et al. Respiratory muscle dynamics and control during exercise with externally imposed expiratory flow limitation. J Appl Physiol 2002;92:1953-63.

47. Bougault V, Lonsdorfer-Wolf E, Charloux A, Richard R, Geny B, Oswald-Mammosser M. Does thoracic bioimpedance accurately determine cardiac output in COPD patients during maximal or intermittent exercise? Chest 2005;127:1122-31.

48. Lalande S, Luoma CE, Miller AD, Johnson BD. Expiratory loading improves cardiac output during exercise in heart failure. Med Sci Sports Exerc 2012;44:2309-14.

49. Hartman JE, Boezen HM, Zuidema MJ, de Greef MHG, ten Hacken NHT. Physical activity recommendations in patients with chronic obstructive pulmonary disease. Respiration 2014;88:92-100.

50. Gloeckl R, Marinov B, Pitta F. Practical recommendations for exercise training in patients with COPD. Eur Respir Rev 2013;22:178-86.

Received for publication: 15 July 2020. Accepted for publication: 16 September 2020.

This work is licensed under a Creative Commons Attribution-NonCommercial 4.0 International License (CC BY-NC 4.0).

(C) Copyright: the Author(s), 2020

Licensee PAGEPress, Italy

Multidisciplinary Respiratory Medicine 2020; 15:702

doi:10.4081/mrm.2020.702 